\section{Energy and Physics}

Third General Conference of the European Physical Society

Bucharest, Romania
9-12 September 1975

Participants in the Third General EPS Conference are invited to register at the earliest possible date. Proper accommodation can only be guaranteed if the registration and the fee is received by 31 July 1975 .

Early registration will also help the organisers of the conference and simplify the customs formalities when entering Romania.

The registration form should be sent to :
A. Corclovel,
Institute for Atomic Physics,
P.O. Box 5206,
Bucharest, Romania.

Eastern participants can pay the registration fee to :

Banque Nationale de Roumanie,

Bucharest,

Account No. 64.41.2.01.43.

Western participants can pay the registration fee to :

Union de Banques Suisses

CH-1211 Geneva 11

Account No, 282.079.30 W

or:

Banque Roumaine

pour le Commerce Extérieur.

Bucharest

Account No. 47.11.032.303-7.

\section{Member Societies}

The Portuguese Physics and Chemistry Society, member according to article $4 \mathrm{~b}$ ) of the EPS Constitution, has split into new Societies namely the "Portuguese Chemistry Society " and the "Portuguese Physical Society". The latter applied for continuing membership with EPS.

\section{Divisions}

Call for nominations. The Board of the European Group for Atomic Spectroscopy (EGAS), section of the Atomic Physics Division, will be renewed this year. During the 7th Conference on Atomic Spectroscopy in Grenoble, 7-11 July 1975, a general Assembly of EGAS will be held. This assembly has to elect three new members to the board. The presentday board will nominate :

J. Bauche, Orsay, M.D. Kunisz, Cracow, and R. Winkler, Berlin, to re-

\title{
EPS Grants to Young Physicists for the Bucharest Conference
}

Two years ago, the Council of the European Physical Society set up a Conference Fund to be used as a solidarity Fund. All Europhysics Conferences, held since September 1974, are paying a capitation fee into the Conference Fund for each of their participants. The Conference Fund will be used for subsidies to young physicists to participate in conferences, to grant small loans to help in starting conferences when no other possibilities are available, and to pay for unexpected losses completely outside the control of the organizers.

It has been decided that the first use of the Conference Fund would be the allocation of grants to young physicists to attend the Third EPS General Conference on Energy and Physics, in Bucharest, next September. An announcement has been published in Europhysics News and applications have been received from physicists from many European countries. The Conference Committee scrutinized these applications; the criteria for selection have been the age, the interests, the previous work, the present position of the candidate and the unavailability of other sources of financing. It was decided to retain mostly candidates from smaller countries as other possibilities on a national basis existed in the larger countries. Twenty grants have been allocated by EPS to young physicists coming from Austria, Belgium, Czechoslovakia, Germany, Great Britain, Hungary, Israel, Italy, Spain, Sweden, The Netherlands and Yugoslavia.

The Executive Committee is very happy that the Conference Fund has thus proved to be useful in helping young physicists to participate in a major international conference.
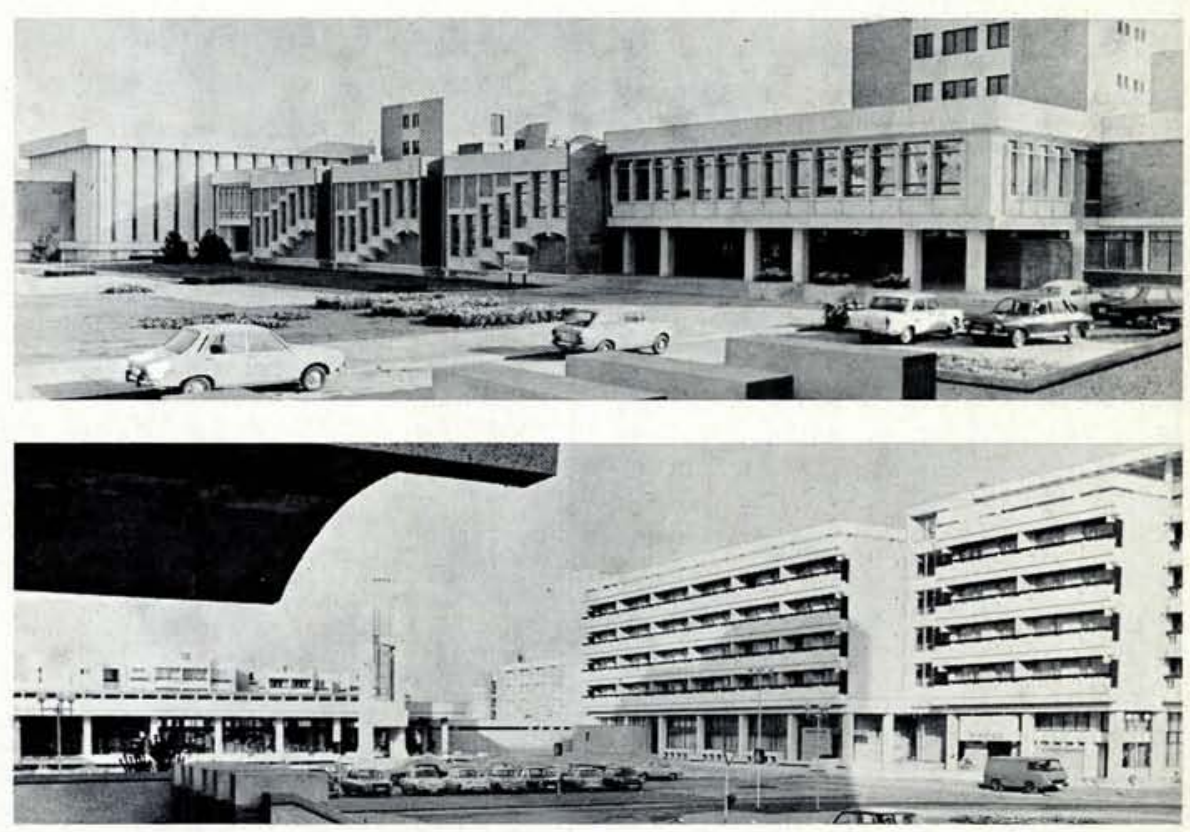

Top : (Photo No. 1)

View of the faculty buildings on the campus of the University of Bucharest.

Bottom : (Photo No. 2)

View of the hotel on the campus.

place J. Blaise, G. zu Putlitz and A. Steudel.

Members of the Section, i. e. Individual Ordinary Members, Constitution Article 4a) and 4c), and National Societies, Academies and Laboratories, Article 4b), can make proposals for further candidates. Nominations should be sent to the Conference Office before 10 July 1975; they should be signed by three EGASmembers and be accompanied by a statement of consent of the nominee.
Editor: L. Sekolec

Editorial Board:

G.J. Béné, B. Glovannini, M. Guenin, B. Hauck, S. Newman, E.N. Shaw.

All correspondence to:

Editor, EUROPHYSICS NEWS,

European Physical Society,

P.O. Box 39,

CH - 1213 Petit-Lancy 2

Phone: Geneva 931132 Switzerland.

Published by the European Physical Society Printed by: Ed. Cherix et Filanosa SA CH - 1260 Nyon, Switzerland 